\title{
PROVOKING ETHICAL AWARENESS AT A DESIGN WORKSHOP ON THE FUTURE OF EDUCATION
}

\author{
Ellen DE VOS ${ }^{1,3}$, Xin XIN², Lieven DE MAREZ ${ }^{4}$, Olivia DE RUYCK ${ }^{3,4}$ and Marina \\ EMMANOUIL ${ }^{1}$ \\ ${ }^{1}$ Research Group design.nexus, Department of Industrial Systems Engineering and Product \\ Design, Ghent University \\ ${ }^{2}$ Beijing Normal University \\ ${ }^{3}$ Research Group imec-mict-UGent, Department of Industrial Systems Engineering and \\ Product Design, Ghent University, Belgium \\ ${ }^{4}$ Research Group imec-mict-UGent, Department of Communication Sciences, Ghent \\ University, Belgium
}

\begin{abstract}
Innovation has been a major force for improving economic and social conditions for humans. Yet, it has also brought a number of unintended and often unpredictable consequences that affect potentially all stakeholders. Debates over 'the responsibility of innovation' have become commonplace in industrial and social forums alike. Technological innovations, especially, are often viewed as a pressure on normative ethics that exclude unrestricted or flexible options. This paper draws upon the outcomes of a 4-day interactive design workshop attended by fifty-six graduate students on the subject of the 'education of the future' at a higher education institution in China. Moral dilemmas were incorporated in the project activities during the design thinking process [1]. By imagining the future of education through creativity techniques, uncertainties from the macro environment of the innovation were revealed and used as tools for the design propositions. This paper aims to illustrate how exploring unknown and potentially problematic situations can help students develop an awareness of the ways ethical considerations can generate legitimate ideas for developing questions that could lead to new design solutions. Although the reflections described in this paper are limited to the experience of the workshop, the value of providing a reproducible framework by which design education facilitators may address ethical dilemmas in problem-based learning contexts, is briefly discussed.
\end{abstract}

\section{Keywords: Innovation, ethics, design workshop, creativity, problem-based design education}

\section{INTRODUCTION}

Ethics refers to open contemplation and debating the norms and values that navigate people in life [2]. One rather new discussion on contemporary ethics is the impact of technology on society making research and innovation (R\&I) in technology accountable for a number of societal issues [3]. In previous years ethical matters about technological innovations where usually evaluated after the production of a product or service and focused mainly on the analytic interpretation of technology (e.g., risks and costs) [4]. Today designers are asked to take informed and ethical decisions on products during the phase of fabrication. Societal actors (e.g., researchers, citizens, policy makers) are increasingly involved in the entire R\&I process aiming at a better match between the process (and its outcomes) and the demands, values and hopes of society [5]. Considering the accelerating speed of technological innovation and the omnipresence of the outcomes of R\&I processes in society, dealing with the latter's ethical impacts is progressively necessary. Especially in the fields of health technologies, information systems and computer science, ethical dilemmas are inherently part of the R\&I process [6]. Although ethics are intrinsic to design in various aspects, Swierstra (2006), Bezerra (2005) and their colleagues point out how designers and engineers tend to leave social responsibility to others on the premise they feel less qualified to act as the agent of change [4], [7]. Indeed, technology design is barely theoretically supported to successfully identify and embed ethical values in design or organise ethical design in the R\&I process [6]. In the broader framework of ethics in design, a responsible designer is seen to be a foreword-looking person who questions the logic of present day 
society and its (ethical) effects when proposing scenarios and alternatives [9]. Hence, the role of educational institutions is fundamental in preparing designers-to-be to handle ethical dilemmas and the vague conditions of detecting and answering constraining needs. This research deals with the broad inquiry of how ethics can become a driving force for innovation in the design process. In specific, it asks how ethics of non-designers can feed the process of innovation and assist designers in formulating a better, ethically-induced design for today and the future. Most importantly, it asks how we can inspire problem-based inquiries and context-specific questions to set the framework for social and technological innovations in the near future. In particular, this research investigates the possibility of how ethical issues can inspire participants to explore the future of education in China in 2030 [11]. Three student examples are selected and presented here: augmented humans who determine and regulate future education; the use of VR technology to shape one's own learning; a game that helps students choose their study programme.

\section{BACKGROUND}

The following sections refer to the workshop's main goals as paths through which students explored the future of education in China (Table 1).

Table 1. Overview of the design workshop

\begin{tabular}{|c|c|c|c|c|}
\hline Day & 1 & 2 & 3 & 4 \\
\hline Goal & $\begin{array}{c}\text { Design reflects on } \\
\text { existing values }\end{array}$ & \multicolumn{2}{|c|}{ Design looks for the possible } & $\begin{array}{c}\text { Design anticipates } \\
\text { on its consequences }\end{array}$ \\
\hline Tool & Context analysis & Science Fiction & $\begin{array}{c}\text { Shaping alternative } \\
\text { futures }\end{array}$ & Product design \\
\hline $\begin{array}{c}\text { Ethics } \\
\text { awareness } \\
\text { exercise }\end{array}$ & $\begin{array}{c}\text { P.E.S.T.E. analysis } \\
\text { on the future of } \\
\text { education }\end{array}$ & $\begin{array}{c}\text { Watch \& discuss an } \\
\text { episode of Black Mirror }\end{array}$ & $\begin{array}{c}\text { Narratives of } \\
\text { different future } \\
\text { scenarios }\end{array}$ & $\begin{array}{c}\text { Product concept } \\
\text { ideation }\end{array}$ \\
\hline
\end{tabular}

\subsection{Design discovers uncertainty}

Designers are customarily invited to delve into and solve ill-defined problems influenced by factors of social, political, economical and ecological nature. Researching and reflecting on existing values and practices helps them to better understand contextual influences. Nevertheless, analytical thinking has not been sufficient to approach solving a complex problem. Design thinking has been defined as a vital approach to solve a problem in a creative manner [12]. In this framework, exploratory activities at the early stages of design are a lot more elaborated than the underlying concept 'idea generation' may suggest. Using one's imagination is useful especially when dealing with phenomena that cannot be directly observed, e.g., change in a social context [13], or when facing uncertainty [6]. By means of scenario building or through foresight methodologies, design searches for the possible. During the explorative identification phase in a design process, the product or service's context that is usually a system of intricate social and cultural changes, is exposed.

\subsection{Design defines}

Manzini and Cullars (1992) claim that imagining new scenarios for alternatives lifestyles is the most unique act of designers, who through their creative skillset visualise plausible future situations that are in principle largely hypothetical and undefined [14]. Moreover, a designers' task often includes the creation of enhanced versions of both the present and the future situation. Such an extended project scoop demands multi-perspectivism, an approach that endorses the value of different points of view in the making of design decisions [15], [16]. Through design, future beliefs and meanings become approachable and exchangeable in the present [17]. Designers have the ability to shape and communicate alternative, technologically advanced futures by means of artefacts and narrative representations. Yet, these materialisations are neither context-free nor a-political acts.

\section{DESIGN WORKSHOP}

\subsection{Overview}

The workshop took place in Beijing Normal University (BNU) in the fall semester 2018. BNU's newly founded master's programme (2016) in User Experience (UX) employs a curriculum that 
recognises the role of design pedagogy. The master's programme is open to students with different undergraduate degrees, e.g., psychology, literature and management science. The majority of students enrolled in this programme lack substantial training in creative techniques. In this workshop only five participants (out of fifty-six) had a background in design, art or architecture. Making non-design students quickly acquainted with design methodology can be challenging. Their design-trained peers have invested 3 to 4 years improving creative, analytical and judgment skills in order to be able to deal with the broader framework of uncertainty when designing and balancing between different stakeholders' priorities and needs [18], [19], [20]. Also, introducing design methodology to nondesigners is not easy due to its (often) non-analytical, open-ended and subjective processes that students with a training in mathematics and literature may not be familiar with [21]. In addition, to implement a design thinking methodology in the Chinese education context is a challenge because Chinese students are not used to student-based discovery and respective pedagogy [22].

Within this four-day workshop, students were performing activities that gave them the opportunity to switch from the micro to the macro environment, and from near to far futures [23]. The future of education was defined as the main topic and students were asked to deliver one elaborated future scenario of an innovative product or service as a final deliverable. Targeted research and creativityinducing methods alternating between divergent and convergent thinking, such as brainstorming and storytelling, were employed. On day 1, participants were asked to do a P.E.S.T.E. analysis (Political, Economic, Sociological, Technological, Ecological) adapted from the ETPS scanning tool [24]. On day 2, literature and science fiction on the topics of privacy, artificial intelligence and security, were employed in order to help students reflect on topical ethical problems. For instance, Black Mirror is a TV sci-fi series that often displays the negative consequences of (technological) innovations, and so this particular series was seen as an apt conversation starter [25]. The discussion of a particular episode was done in small groups. On day 3, students were asked to shape different future scenarios in 2030 by mixing their factual data with fiction material stemmed from their imagination. The latter task included three sub-activities: first, ranking 'drivers' of innovation in terms of uncertainty and impact on the future; second, adopting a structure to develop four scenarios; and, third, refining the storyline of each scenario that encompassed the visions for the future. On the last day (4), students presented their suggestions for products and services within one possible future in the presence of a design director, an artist and a university representative.

\subsection{Tool 1: P.E.S.T.E. analysis}

Since the mid-twentieth century the velocity at which evolutions have occurred at the cultural, economic, technologic and social level has become more apparent [26]. These changes influence the environment that is the frame of reference on which all design decisions are based. In consequence, context exploration is indicated to be the first step in design [27]. To understand better the context, P.E.S.T.E. analysis was used to probe ethical questions. Here below are some basic and some more elaborate questions posed by the participants after using this tool. On a political level, students wonder who will be responsible for the study quality and accessibility to study programmes. Will there be laws in the virtual world? What if robots start controlling humans? How (and where) will experiments with new technologies be feasible? Should the government protect and warn its citizens for the side effects? On the level of economy, although the emerging technologies of today will most likely be implemented on a large scale by 2030, the students fear high costs. Will there still be money left to pay teachers? Will all citizens pay extra taxes for the innovation of education? Is data tradable? Will inequality among people grow (due to their financial capacity), and which effect on the accessibility of education will this have? On a social level, many questions concerned the relation between the parents, the school and the student: who should advise and discipline the student? How addictive are technologies in a virtual and augmented reality? What if technology makes us lazy instead of intelligent? Will technology kill our personality and creativity? What will be the mental impact of isolated online classes or long periods in virtual reality? On the technological level, adapting to innovation requires a kind of trust in the technologies of tomorrow. What if someone can hack the technology and violate the rules? Should the limitations of technology implementations be discussed, or is the sky the limit? Lastly, on the ecological level, as most new technologies rely on electricity supply, would innovative teaching materials cause environmental pollution? How (un)limited are the resources? Will we lose touch with nature? 


\subsection{Tool 2: Factors in a matrix for future scenario building}

The next objective was to examine the interaction of two impactful and highly uncertain evolutions through the use of a matrix (Table 2). The $\mathrm{X} / \mathrm{Y}$ axes identify the alternative directions in which these factors could evolve in 2030. Selecting these evolutions was a crucial step. The selection process was not based on what could lead towards merely a 'better' or a 'worse' outcome. The matrix would potentially allow more space for participants to elaborate further and from their own value judgments [28]. The students grouped in 11 teams, imagined scenarios in four quadrants of a matrix. This input served as a base for their design propositions either in the form of a product or service.

Table 2. The matrix of factors influencing scenarios

\begin{tabular}{|c|l|l|}
\hline Team & \multicolumn{1}{|c|}{ X-axis } & \multicolumn{1}{c|}{ Y-axis } \\
\hline A & Individual vs. teamwork & Control: human vs. machine \\
\hline B & Limited vs. unlimited & Care: about all species vs. only about humans \\
\hline C & (Not documented) & (Not documented) \\
\hline D & No privacy vs. privacy highly protected & Wellbeing: public vs. commercial \\
\hline E & Emotional stimulation: low vs. high & Human autonomy: low vs. high \\
\hline F & Temporary vs. permanent & Inequality: mental vs. physical \\
\hline G & Frequency: low vs. high & Ease of use: low vs. high \\
\hline H & Virtual vs. real & Rational vs. emotional \\
\hline I & Context: virtual vs. real & Individualism vs. collectivism \\
\hline J & Efficiency: low vs. high & Adaptability: low vs. high \\
\hline K & Immaterial vs. material & Users: special vs. common \\
\hline
\end{tabular}

\subsection{Selected student ideas for the future of education}

\subsubsection{Augmented humans}

Team F implemented the emerging technology 'augmented human' in four products (Fig. 1): The glove that was initially designed for disabled people sets new standards in (perfect) handwriting. The bionic hands: imagine a basketball match where a team with bionic hands is competing with ordinary human players. Should the government draw rules about fair play? Study drugs: the need of drugs to increase productivity is becoming an emerging concern among students in 2030. What will happen when people are used to the drug's effects and need a higher dosage to satisfy their needs? Lastly, DNA modification: a genius student discovers at the age of sixteen that his parents modified his DNA. He questions his identity: is he a human, a robot or a cyborg?

\subsubsection{Learn with VR glasses through your own experience}

The proposed product of team B is a personal device that can be used to learn from one's own virtual experiences (Fig. 2). The combination of learning and entertainment could trigger the motivation of students. In the example given, a student learns how to reach the top of Mount Everest by virtual trainings on the expected conditions. While the autonomy of the students increases in a virtual world, will they keep touch with reality and its tangible challenges?

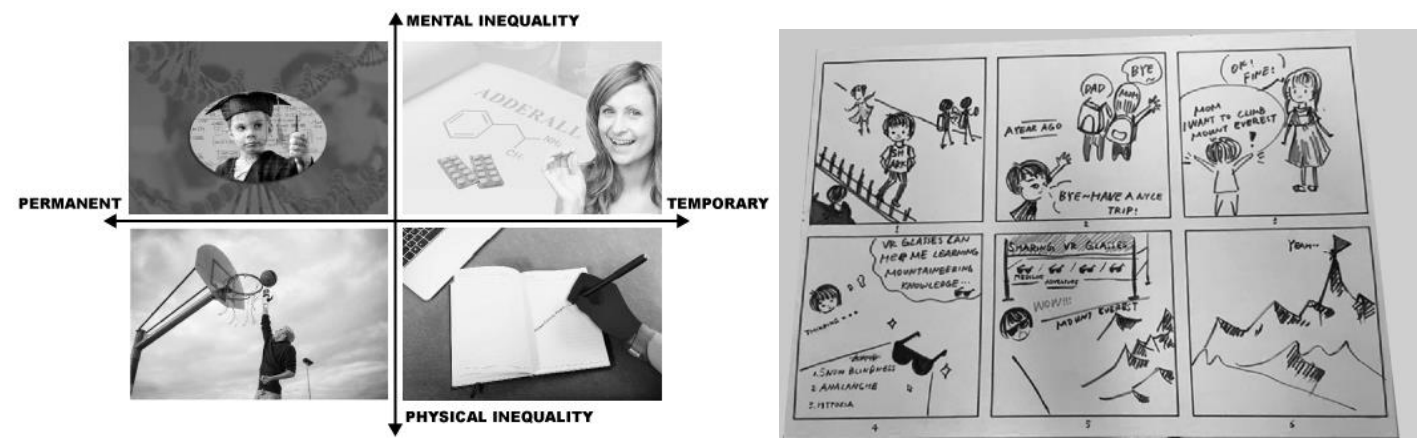

Figure 1. Four 'augmented human' product ideas (left)

Figure 2. A storyboard on VR experience (right) 


\subsubsection{Study-programme selection game}

This tool designed by team $\mathbf{J}$ advises youngsters who have difficulties selecting a study programme (Fig. 3). The result fits with their personality and guarantees future-proof jobs. This product would help many Chinese students who are nowadays suffering from great pressure about their study programme choice [29]. Most of them only get one chance and therefore cannot afford a wrong choice. Trends like big data and gamification are implemented in this idea.
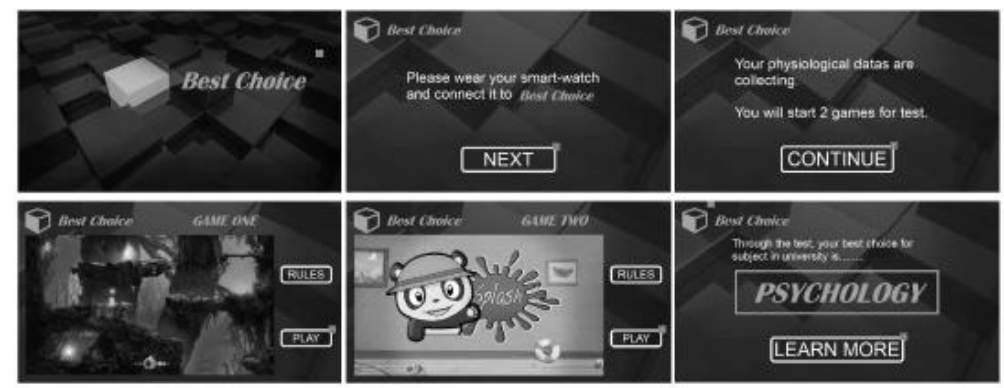

Figure 3. Study-programme selection game

\section{DISCUSSION AND FURTHER WORK}

Building ethical awareness was the main goal of the workshop. The objective was to help non-design UX students take on a design project and think like a designer. Reflections on existing values and the changing circumstances were introduced in a design-for-2030 project. The performed extensive problem exploration and decision-making based on discussing alternatives are both actions that can be appreciated as 'responsible'. However, in future, students should not only be encouraged to reconsider given circumstantial limitations but widen the problem space. They could also be stimulated to suggest alternatives in advance of unwanted secondary effects of their own designs [23]. These invisible parameters of design could lead towards beneficial outcomes, knowing that more ethics will be questioned with the growth of new technical developments [30], [31], [6]. Students showed an elevated view of design responsibility during the workshop. Whereas individual ethics are crucial to design practice, design institutions need to develop curricula directed towards training all students in thinking and acting ethically in a systematic way [32]. It becomes increasingly urgent to incorporate ethics continuously and persistently throughout the curriculum, and not only through occasional events [1]. The value of providing a reproducible framework by which design education facilitators may address ethical dilemmas in problem-based learning contexts is discussed. In forthcoming research we intend to investigate further into the effect of the workshop on students' level of ethics.

\section{REFERENCES}

[1] Skirpan M., Beard N., Bhaduri S., Fiesler C. and Yeh T. Ethics Education in Context: A Case Study of Novel Ethics Activities for the CS Classroom. In Proceedings of the 49th ACM Technical Symposium on Computer Science Education, Ethics SIGCSE'18, February 2018, Baltimore.

[2] Swierstra T. Introduction to the Ethics of New and Emerging Science and Technology. In Handbook of Digital Games and Entertainment Technologies, 2017, 1271-1295.

[3] Owen R., Macnaghten P. and Stilgoe J. Responsible research and innovation: From science in society to science for society, with society. Science and Public Policy, 2012, 39(6), 751-760.

[4] Swierstra T. and Jelsma J. Responsibility without moralism in technoscientific design practice. Science, technology, \& human values, 2006, 31(3), pp. 309-332.

[5] Geoghegan-Quinn M. Responsible research \& innovation. Europe's ability to respond to societal challenges. In Proceedings of the Science in Dialogue-Towards a European Model for Responsible Research and Innovation, Odense, 2012, 23-25.

[6] Reijers W., Wright D., Brey P., Weber K., Rodrigues R., O'Sullivan D. and Gordijn B. Methods for Practising Ethics in Research and Innovation: A Literature Review, Critical Analysis and Recommendations. Science and Engineering Ethics, 2018, 24, 1437-1481. 
[7] Bezerra C. and Brasell-Jones M. Design Responsibility in Global Open Societies. In Conference Proceedings Joining Forces International Conference on Design Research. University of Art and Design (2005, Helsinki).

[8] Parsons G. The Philosophy of Design. 2016 (Polity, UK).

[9] Leerberg M., Riisberg V. and Boutrup J. Design responsibility and sustainable design as reflective practice: An educational challenge. Sustainable Development, 2010, 18(5), pp. 306317.

[10] Feland J.M., Leifer L.J. and Cockayne W.R. Comprehensive design engineering: Designers taking responsibility. International Journal of Engineering Education, 2004, 20(3), pp. 416-423.

[11] Devon R. and van de Poel I. Design ethics: The social ethics paradigm. International Journal of Engineering Education, 2004, 20(3), 461-469.

[12] Johansson-Söldberg U., Woodilla J. and Çetinkaya M. Design thinking: past, present and possible futures. Creativity and innovation management, 2013, 22(2), pp. 121-146.

[13] Hadzigeorgiou Y. Imaginative Thinking in Science and Science Education. In Imaginative Science Education, 2016 (Springer, Cham).

[14] Manzini E. and Cullars J. Prometheus of the Everyday: The Ecology of the Artificial and the Designer's Responsibility. Design Issues, 1992, 9(1), pp. 5-20.

[15] Adams R., Daly S., Mann L., Dall’Alba G. Being a professional: Three lenses into design thinking, acting, and being. Design Studies, 2011, 32(6), 588-607.

[16] Kleinsmann M., Valkenburg R. and Sluijs J. Capturing the value of design thinking in different innovation practices. International Journal of Design, 2017, 11(2), 25-40.

[17] Gatto G. and McCardle J. The designer and the scientist: The road to inspire transdisciplinary synergies, 2016.

[18] Lande M. and Leifer L. Incubating engineers, hatching design thinkers: Mechanical engineering students learning design through ambidextrous ways of thinking. In Proceedings of the Annual American Society for Engineering Education Conference, 2010, Louisville.

[19] Tracey M.W. and Hutchinson A. Getting to Know the Unknown: Shifts in Uncertainty Orientation in a Graduate Design Course. In Proceedings of the $3^{\text {rd }}$ International Conference for Design Education Researchers, 2015.

[20] RAE. Creating systems that work: Principles of engineering for the $21^{\text {st }}$ century. Royal Academy of Engineering, 2007, London.

[21] Oswald D. From ethics to politics: if design is problem solving, what then are the problems? In DS 83: Proceedings of the 18th International Conference on Engineering and Product Design Education (E\&PDE16), Design Education: Collaboration and Cross-Disciplinarity, 8th-9th September 2016, Aalborg.

[22] Jin L. Cortazzi M. Changing practices in Chinese cultures of learning. Language, Culture and Curriculum, 2006, 19(1), 5-20.

[23] Spencer N., Bentham A., Baylis B. and Sams P. What on Earth is Responsible Innovation anyway? (And how to make it happen). 2016.

[24] Aguilar F.J. Scanning the business environment. 1967 (Macmillan).

[25] Pandit H.J. and Lewis D. Ease and Ethics of User Profiling in Black Mirror. In $W W W^{\prime} 18$ Companion: The 2018 Web Conference Companion, Lyon, April 2018.

[26] Guemes-Castorena D. Megatrend methodology to identify development opportunities. In PICMET Proceedings 6, Portland International Conference, 2009, pp. 2391-2396.

[27] Hekkert P. and Van Dijk M. ViP-Vision in Design: A Guidebook for Innovators, 2011 (BIS Publishers).

[28] Raven P.G. and Elahi S. The New Narrative: Applying narratology to the shaping of futures outputs. Futures, 2015, 74, pp. 49-61.

[29] Yuxin Y. A Study on Equity of Opportunity to Learn. PhD, East China Normal University, 2018.

[30] Burckhardt L. Design is invisible. In Rethinking Man-made Environments: Politics, Landscape and Design, 2012, pp.153-165 (Spring-Verlag, Vienna)

[31] Stahl B.C. Virtual suicide and other ethical issues of emerging information technologies. Futures, 2013, 50, pp. 35-43.

[32] Findeli A. Rethinking Design Education for the 21st Century: Theoretical, Methodological, and Ethical Discussion. Design Issues, 2001, 17(1). 